\title{
An Enhanced Learning Technology System Architecture for Web-Based Instructional Design
}

\author{
http://dx.doi.org/10.3991/ijet.v11i01.4930 \\ R.M. Isiaka ${ }^{1}$, E.O. Omidiora ${ }^{2}$, S.O. Olabiyisi ${ }^{2}$ and O.O. Okediran ${ }^{2}$ \\ ${ }^{1}$ Kwara State University, Malete, Ilorin, Nigeria \\ ${ }^{2}$ Ladoke Akintola University of Technology, Ogbomoso, Nigeria
}

\begin{abstract}
Instructional design (ID) models are proven prescriptive techniques for qualitative lessons that could guarantee learning. Existing Learning Management Systems (LMS) miss-out the roles of this important quality control mechanism by providing a mere plane and passive platform for content authoring, thus becomes vulnerable for poor instructional design. This paper demonstrates an effort to ameliorate this limitation by extending the IEEE Learning Technology System Architecture (LTSA) with ID design processes. The Use Case diagram, Activities diagram and Entity Relation diagram for the extended LTSA are presented. The extended architecture was implemented on Moodle open sourced LMS which was extended and hosted live. Students' impressions on the functionalities and operational effects of the platform were collated using online survey. The academic effects of the platform on the students' performance were determined using the class mean. The value obtained was compared with that of the control group in the same session and those from the previous sessions. Consequently, this work demonstrates the feasibility of integrating ID models in E-learning. It also justifies its effects on the quality of learning.
\end{abstract}

Index Terms-E-learning Standards, Instructional Model Design, Learning Management Systems (LMS), IEEELTSA.

\section{INTRODUCTION}

Ability to produce a good Instruction design (ID) is one of the competences expected of a tutor. Tutors are also expected to perform satisfactorily in lesson delivery, class control and class evaluation. An effective ID must be based on ID models that are based on Instructional theories which is built on established learning theories [7]. Invariably, ID based on tutor's intuitions only is vulnerable to poor design which may not guarantee learning. The effects of such inadequacy became graver when it is meant for E-learning platforms. Instructional theories are practice oriented theories offering explicit guidance on how to help people learn [3]. Systematic teaching/ learning components developed by using certain learning and instructional theories are referred to as Instructional Design models [3].

Contemporary Content Management System (CMS) and Learning Management Systems (LMS) are limited in their capabilities to support instructional design based on Instructional models. They have been criticized for lacking proper pedagogical affordances and limited content management capabilities [4].The task of actual ID is currently put at the liberty of the tutors who may not be expert instructional designers. Even when the tutors have some ID skills, the best they could do is to perform the design externally and approach the LMS for design implementation or content authoring without any design quality verification mechanism. Hence, for lack of monitoring and guidance, an online-lesson may be poorly packaged such that learning may not take place in the student.

In conventional educational system, teachers are physically available to monitor students' extent of commitments to their studies through the school records [9]. As such they could device adequate corrective measures when found to be deficient. Similarly teachers could psychologically determine the mood of the class during lessons and promptly make necessary pedagogical adjustments that suite the observed impressions. However, since the face-to-face teacher/learners' interactions is missing in most virtual classes it will be highly detrimental to have a poorly designed online lessons.

To ameliorate the identified limitations, it is essential to introduce ID processes as an integral component of Elearning systems. For adequate implementation, such action has to be performed on a generic system conceptualization model. This paper demonstrates the methodology adopted for ID process extension on the Institute of Electrical and Electronic Engineers - Learning Technology System Architectures (IEEE-LTSA).

\section{LEARNING DESIGN MODELS}

The terms Instructional Design (ID) and Learning Design (LD) are interchangeable used to describe instructional experiences which make the acquisition of knowledge and skill more efficient, effective and appealing [6]. However, [2] regards LD as the final artefact of the ID processes. ID is a systematic process that is employed to develop education and training programs in a consistent and reliable fashion [8]. The processes are based on well researched and well tested pedagogical theories of teaching. They assumed that if appropriate process is used to package instructions, learning will take place, the outcome may either be observable or assumed. Though ID model is relatively new for web-based Elearning systems, it is quite a familiar practice in conventional system of education. [10] traced the concept of "Instructional design" to the B.F. Skinner's article titled "The Science of Learning and the Art of Teaching" in 1954.

ID models are said to be prescriptive because they provide guidelines or framework for organizing, structuring and creating Instructional activities. Common examples of instructional design models are Merrill's First Principle of 
Instruction, ADDIE Model, Dick and Carey Model, Kemp's Instructional Design Model and Gagne's Nine Events of Instruction. Others are John Keller's ARCs model, Jeroen Van Merriemboer,s 4C/ID model and Lev Landa's Algo-Hueristic Theory.

\section{E-LEARNING STANDARDS AND STANDARD BODIES}

The Standard can generally be defined as "documented agreements containing technical specifications or other precise criteria to be used consistently as rules, guidelines or definitions of characteristics, to ensure that materials, products, processes and services are fit for their purposes" [5]. Standard is said to be a de jure standard if it emerges by official directives or by law, but it is known as a de facto standard when it is a product of popular convention or general acceptability [11]. The significance of standard appears in all spheres of human existence. The quest to ameliorate the effects of high costs of developing educational contents that are not portable to other platforms prompted some organizations to proffering patterns and guidelines for E-learning contents and components [1]. A handful of such organizations and bodies that have contributed to the development of E-learning standards are generally refers to as E-learning Standard Bodies.

IEEE is one of the bodies that have contributed immensely to e-learning standardizations. Other prominent bodies include International Standards Organization (ISO) - http://www.bsi-global.com, Instructional Management Systems (IMS Global Learning Consortium), http://www.imsglobal.org, Aviation Industry CBT Committee (AICC) accessible at AICC -http://www.aicc.org and Advanced Distributed Learning Initiative (ADL) http://www.adlnet.org. Others are DCMI - Dublin Core Metadata Initiative - http://www.dublincore.org. The standards promulgated by these bodies could be in the area of Metadata, Content packaging, Learner Profile, Learner Registration, Content Communication or System Conceptualization. The standard bodies and their areas of contribution are as summarized in table 1:

However, as shown in table I, IEEE is one of the few standard bodies that provide System Conceptualization standard.

\section{E- LEARNING STANDARDS AND CORRESPONDING STANDARD BODIES}

The IEEE Learning Technology System Architecture (IEEE-LTSA) is from the family of IEEE Standards for Learning Technology Systems (Bianco et.al., 2013). The reference number for the IEEE- LTSC is 'IEEE Std 1484.1-2003'. It is one of the releases of standards sponsored by the Learning Technology Standard Committee of IEEE Computer Society. The contents of the standard provide informative and normative technical descriptions of a Learning Technology System Architecture (LTSA). The informative wordings provide helpful information, clarifications of the text, examples and guidance. They do not contain any technical requirement and therefore they do not form an integral part of this standard. The normative wordings on the other hand are the essence of this standard. It specifies the technical requirement and conformity assessment that is based on normative wording. Figure 1 shows the five layers of IEEE-LTSA.

The architecture is a generic five layers high level architecture for Information Technology. It is not a blue- print for a particular training system hence it is a pedagogical, cultural and platform neutral model. Four of these layers are informative while the third layer (layer 3 - the system components) is normative. The five layers are Learner and Environment Interactions (informative), Learner-Related Design Features (informative), System Components (normative), Implementation Perspectives and Priorities (informative) and Operational Components and Interoperability - codings, APIs, protocols (informative).

TABLE I.

E-LEARNING STANDARDS, PURPOSES AND BODIES

\begin{tabular}{|c|c|c|c|c|c|c|c|}
\hline \multirow[t]{2}{*}{ Standards } & \multirow[t]{2}{*}{ Purpose } & \multicolumn{6}{|c|}{$\begin{array}{l}\text { Standard Bodies } \\
\text { (A: IMS, B: ADL, } \\
\text { C: Dublin Core, D: } \\
\text { IEEE-LTSA, E: } \\
\text { ISO, F: AICC) } \\
\end{array}$} \\
\hline & & $A$ & $B$ & $C$ & $D$ & $E$ & $F$ \\
\hline Metadata & $\begin{array}{l}\text { Labeling and indexing of content for } \\
\text { easy storage, search and retrieval } \\
\text { across repositories and platforms. }\end{array}$ & $\sqrt{ }$ & & $\sqrt{ }$ & $\sqrt{ }$ & $\sqrt{ }$ & \\
\hline $\begin{array}{l}\text { Content } \\
\text { Packaging }\end{array}$ & $\begin{array}{l}\text { Specifications for inter-operability } \\
\text { of courses among learning systems. } \\
\text { It comprises of the learning con- } \\
\text { tents, the instructions, the rules, the } \\
\text { sequence and navigations. }\end{array}$ & $\sqrt{ }$ & $\sqrt{ }$ & & $\sqrt{ }$ & $\sqrt{ }$ & $\sqrt{ }$ \\
\hline $\begin{array}{l}\text { Learner } \\
\text { Profile }\end{array}$ & $\begin{array}{l}\text { Designed to allow exchange of } \\
\text { learner information across systems } \\
\text { and platforms. It usually include } \\
\text { personal data, learning plans, learn- } \\
\text { ing history, accessibility require- } \\
\text { ments, certifications and progress. }\end{array}$ & $\sqrt{ }$ & & & $\sqrt{ }$ & $\sqrt{ }$ & \\
\hline $\begin{array}{l}\text { Learner } \\
\text { Registration }\end{array}$ & $\begin{array}{l}\text { Determine what offerings should be } \\
\text { made available to a learner via the } \\
\text { Learner registration information. }\end{array}$ & $\sqrt{ }$ & & & $\sqrt{ }$ & $\sqrt{ }$ & \\
\hline $\begin{array}{l}\text { Content } \\
\text { Communi- } \\
\text { cation }\end{array}$ & $\begin{array}{l}\text { Standardized communication proto- } \\
\text { cols and data models for sharing } \\
\text { learner competency, course grade } \\
\text { and completion }\end{array}$ & $\sqrt{ }$ & $\sqrt{ }$ & & $\sqrt{ }$ & $\sqrt{ }$ & \\
\hline $\begin{array}{l}\text { System } \\
\text { Conceptua- } \\
\text { lization }\end{array}$ & $\begin{array}{l}\text { Developed to ensure generic and } \\
\text { theoretical solutions to compare and } \\
\text { harmonize the entities and objects in } \\
\text { E-learning systems. }\end{array}$ & $\sqrt{ }$ & & & $\sqrt{ }$ & & \\
\hline
\end{tabular}
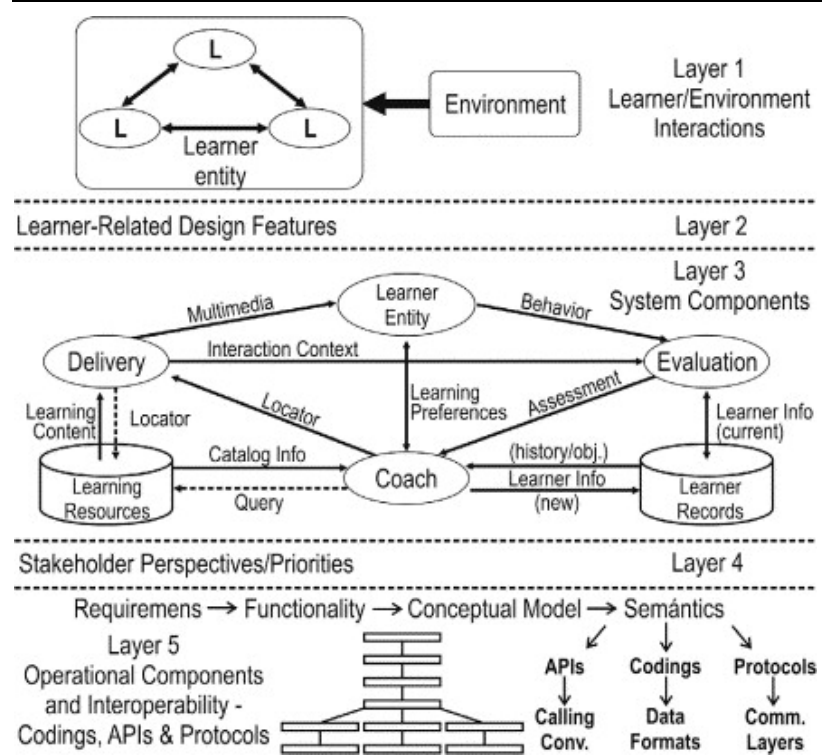

Figure 1. The LTSA abstraction-implementation layers. (IEEE 1484 LTSA, 2001) 


\section{IEEE-LTSA SYSTEM COMPONENTS LAYER'S EXTENSION}

Originally, LTSA System Component layer (layer3 in figure 1) identifies four processes (learner entity, evaluation, coach, and delivery process), two stores (learner records and learning resources) and thirteen information flows (behavioral observations, assessment information, learner information (three times), query, catalog info, locator (twice), learning content, multimedia, interaction context, and learning preferences). The Architecture for Web-Based Instructional Design in figure 2 reflects the modification on IEEE LTSA to accommodate pedagogical content packaging.

The Architecture in figure 2 identifies three actors for elearning lesson design. The actors are the lesson designer, the content author and the lesson tutor. The Coach in the IEEE-LTSA was expanded to accommodate the three actors. Any of the actors could play the role of the Coach in LTSA. This is because activities of the trios require accessing and understanding the learner information, the lesson objective and subject domain. Instructional designer uses the science and art of Instructional Design to build instructions by adopting Instructional Designer models. The formulated Learning Design can be contributed to the repository for future reuse or adoption. Content author in the same vain uses relevant content authoring tools to create learning objects or SCOs in SCORM as the case may be, the learning objects can be save into repository for references. Similarly, a lesson tutor formulates a unit of learning (a course or a lesson) by making appropriate choice from collections of Instructional design models, learning design and learning objects. When all that are required are found in the repositories the tutor may not need to reinvent the wheel rather the task would only be to sequence learning activities appropriately. When satisfactorily done, the lesson is saved into the lesson repository for learners to access via compatible delivery and monitoring system or LMS.

The Use Case Diagram for the Web-Based Instructional Design Architecture is as shown in Figure 3.

\section{PEDAGOgicAl GROUNDEd InSTRUC-TionaL DESIGN}

A lesson or unit of learning (UoL) is the product of Instructional Design. In this study, CSC 306 titled System Analysis and Design was packaged using the extended Moodle platform. Unlike the default course packaging platform, in this case, the tutor is carefully guided by series of steps as contained in the instructional design model selected. Activity diagram for a typical unit of learning is as shown in figure 4 . The diagram in figure 4 demonstrates a case for Gagne instructional design model. The diagram depicts that the tutor needs to specify the objective or the purpose of the lesson by 'Describing the course'. All assets considered to be necessary must be collected or build. If such assets are found in the repository they can be adopted or adapted to suite the intended lesson. Having collected all required assets, the next action is to specify the tasks which inform the choice of learning design model. The intended model can be searched in the repository, if exact model is found it can be adopted otherwise some form of modification may be made or a new model may be created and save in the repository. The collected assets and services will be inte-

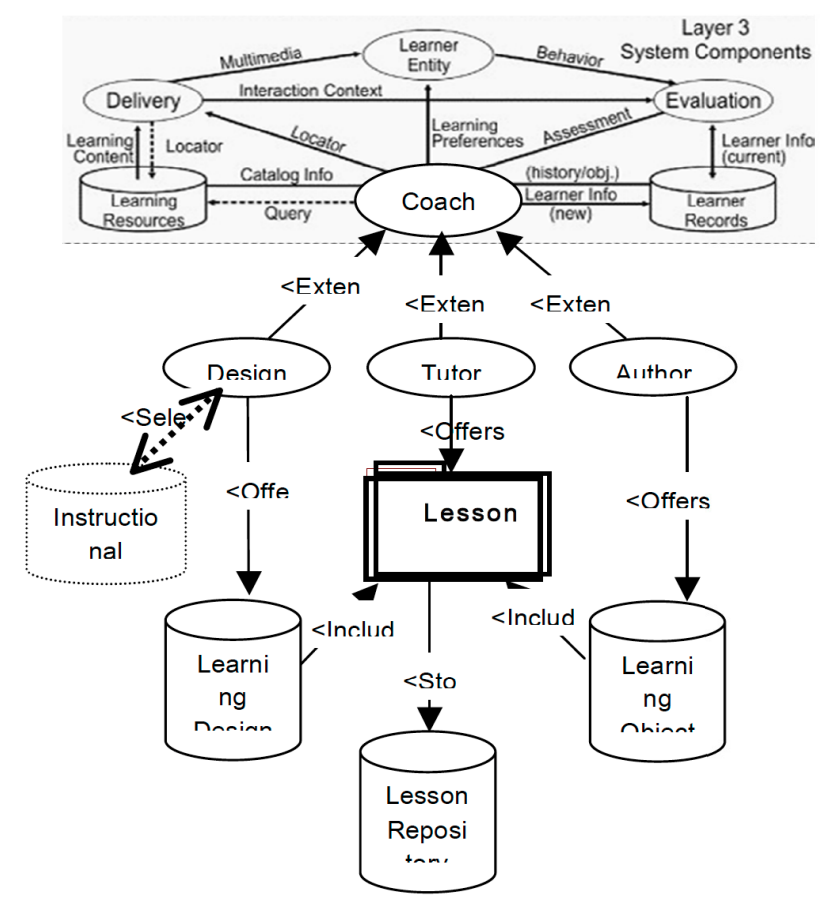

Figure 2. The Architecture for Web-Based Instructional Design

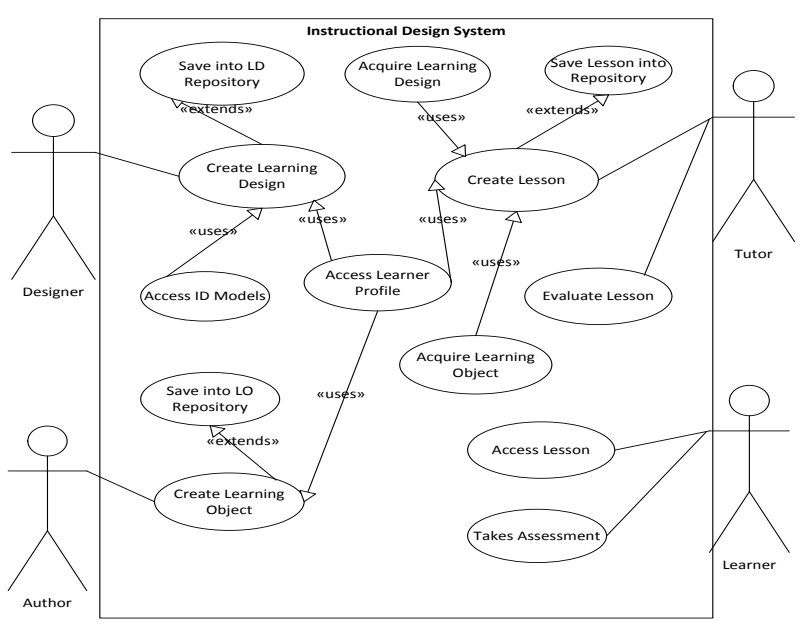

Figure 3. Use Case Diagram for Web-Based Instructional Design Architecture

grated into the design model. Performance thresholds will be set and the course will be package and store in the lesson repository. Finally alert may be sent to stakeholders to announce the creation of the lesson.

\section{WEB-BASED INSTRUCTIONAL DESIGN IMPLEMENTATION IN MOODLE}

Modular Object-Oriented Dynamic Learning Environment (Moodle) is an open sourced platform built on threetier architecture. The first tier is the Database (backend) layer that consists of over 200 tables. It is commonly deployed using MySQL Database Management Systems (DBMS) though it is compatible with several other DBMS such as Oracle and SQLServer. The choice of MySQL for Moodle deployment is significantly informed by the fact that the duo of MySQL and Hypertext Pre-Processing (PHP) programming language areopen-sourced. The second tier is the application processing (middle) layer. It consists of PHP modules in their hundreds, each one of 


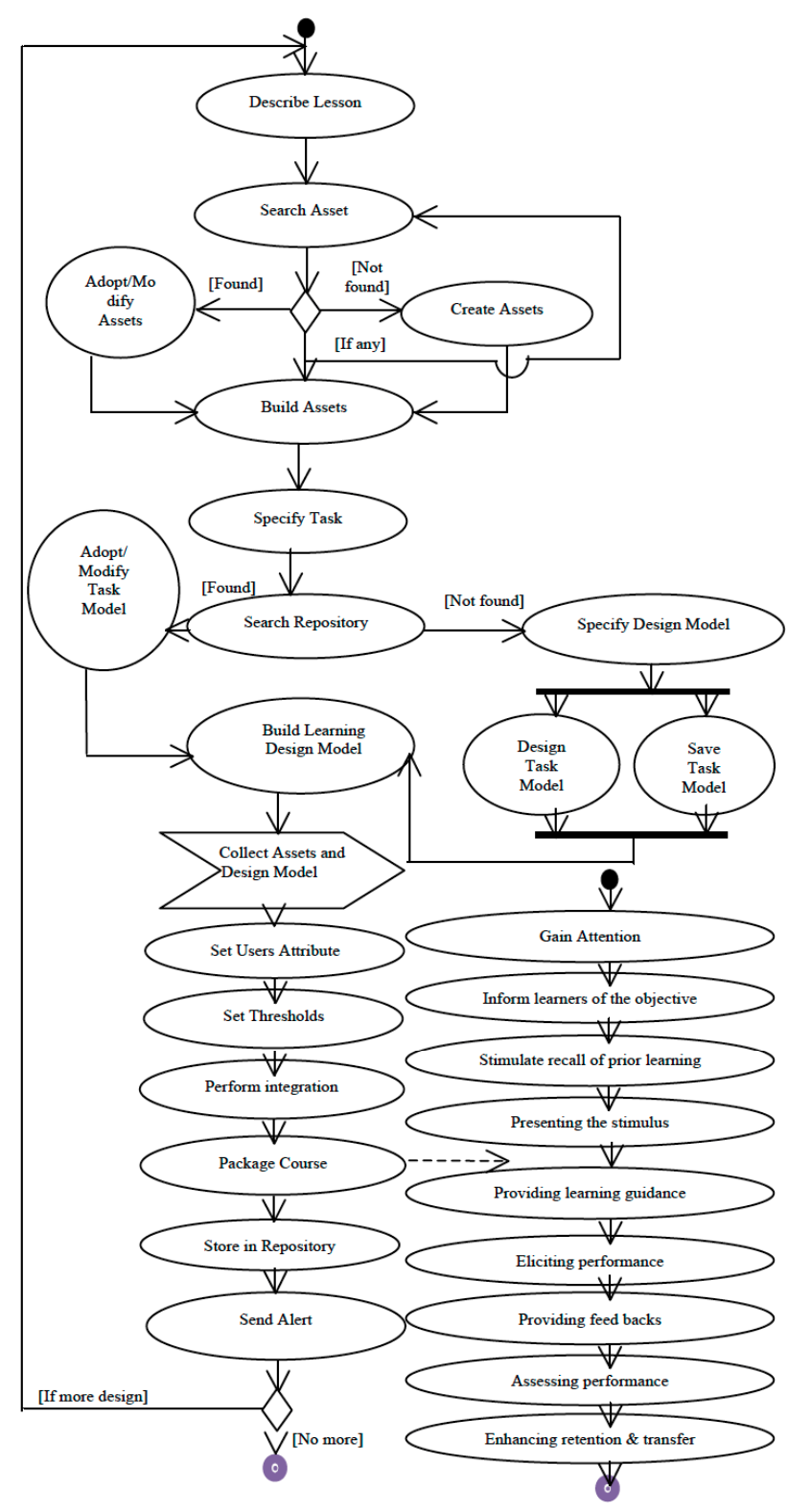

Figure 4. Activity Diagram for Instructional Design Grounded in Gagne

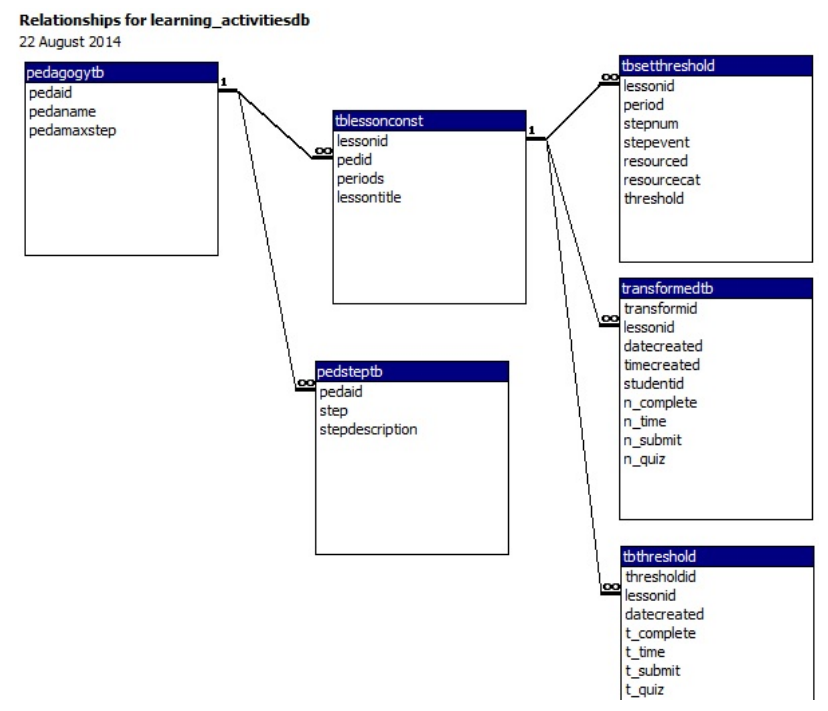

Figure 5. Entity Relationship Model for Learning Design them performs specific functions. The third architectural level in Moodle is the GUI- Graphical Users Interface (Frontend) tier. The interface serves as the platform for interaction between the users and Moodle. The interface is built using HTML, JavaScript and JQuery languages. In view of these, the integration of the learning design and packaging architecture in Moodle is accomplished by extending the three tiers of the architecture. The Data model for this core extension is as shown in figure 5.

Figure 5 illustrates the six (6) tables that extend the Moodle database. It illustrates the interactions between six out of the eleven table in one (I) to many $(\infty)$ relationships. The integrity of the model is ensured by the activation of its referential integrity. By this, only existing lesson id can be referenced as foreign key.

\section{EVAluation Of Web-BASEd InStructionAL DESIGN IN MOODLE}

The effectiveness of the architecture implemented in Moodle was evaluated using usability, acceptability and impacts as metrics. The usability of the platform in this context is considered to be the functions of how it meets the essence for which it was setup. Online survey was conducted after a month into the implementation as an instrument for formative assessment. The intent was to elicit the perceptions of the students and to provide a feedback to the teacher. Thereby providing bases for enhancement and adjustment were necessary. In all fortyfive (45) students participated in the survey, their responses to eight (8) out of the eleven questions in the survey are shown in the table. The remaining three are open questions with diverse responses. The survey reveals that $75.56 \%$ of the respondents agreed that platform increases their commitments to the course. $80 \%$ of them submitted that the platform increases interactivity with classmates. All the respondents $(100 \%)$ admitted that the platform fosters quest for searching relevant course materials. On the request to rate the course sequencing approaches being used by the teacher, 53.33\% rated it as good and $40.00 \%$ as fair. Combination of the two figures is $93.33 \%$ which is very okay, however the reasons for the remaining $6.67 \%$ that rated the sequence as poor are of concern. It was given an immediate attention because the poor rating was sustained in the question on students' level of understanding, while the percentage for the Good rating was surpassed by the Fair rating. Ordinarily, answers to question number 5 suppose to be a perfect reflection of that in question number 4. Question number 6 on Internet connectivity method(s) shows that $80.00 \%$ of students used the University Network (KWASUNET), follow by Mobile ISP Modems and lastly the Internet Cafes. This survey result divulges the gradual preference of Mobile ISP Modem powered by mobile telecommunication networks over the café services for internet connectivity by users. The question on the type of computing devices used by the students allows an overlapping answers, this is because a particular student could use more than one type of devices overtime. In all 93.33\% used Laptops, 55.56\% used Smart phone, $17.78 \%$ used Desktop followed by $6.67 \%$ that used Tablets. In all $53.33 \%$ of the students are ready to take more courses online while $46.67 \%$ have some reservations. The reasons for the $46.67 \%$ saying 'NO' to the offer of more courses online are not unconnected to the current challenges of Electricity, Internet connectivity and the first timer syndrome. 


\section{ANALYSIS OF LEARNERS ACADEMIC PERFORMANCE}

Finally the overall impacts of this model on the academic performance of the students were measured. Descriptive statistics; the grade percentages and the class mean were used. The performance of students in CSC 306 in the $2011 / 2012,2012 / 2013$ sessions were compared with that of 2013/2014 in which the developed model was implemented. The summaries are as in table II.

The Graph of the students performances are shown in figure 6 .

The graph reveals that students' performances in $2013 / 2014$ outperformed that of the two previous years. The mean value of the $2013 / 2014$ set is 56.98 , that of the $2012 / 2013$ set is 53 and in 2011/2012, the class mean is 37 . The percentage failure was $3.39 \%$ in $2013 / 2014$, it was $12.77 \%$ in $2012 / 2013$ and the worst case was $56 \%$ in $2011 / 2012$.

\section{CONClusion}

The feasibility and essence of integrating instructional design models into Learning Management System are demonstrated in this paper. The future work would focus on an investigation into the awareness level and extent of application of ID models among lectures in Nigeria Tertiary Institutions.

\section{REFERENCES}

[1] A. Blanco, A. Serano, M. Freire, I. Mentinez, and B. Fremandez, "E-learning Standards and Learning Analytics: Can Data Collection Be Improved by Using Standard Data Model?", 2013 IEEE Global Engineering Education Conference (EDUCON), Berlin Germany, pp 1255-1261, 2013 http://dx.doi.org/10.1109/ EduCon.2013.6530268

[2] A.S. Miguel, D.L.Miltiadis, S.A.Salvador, G.B. Elena, and Z.R.Miguel, "Modeling instructional-design theories with ontologies: using methods to check, generate and search learning design," Computer in Human Behaviour, Elsevier, Vol. 27, pp. 1389 -1398, 2011 http://dx.doi.org/10.1016/j.chb.2010.07.040

[3] C.M. Reigeluth (Ed), "Instructional-design theories and models," A New Paradigm of Instructional Theory, Vol. 2. Mahwah, NJ: Lawrence Erlbaum Associates, 1999.

[4] D. Zhang, S. Shaw, and S. Johannes, "Embedding instructional design support in course management system - Implications from Literature Review," Proceedings of World Conference on Educational Multimedia and Telecommunications, FL USA, pp. 880887, 2006.

[5] ISO, "The magical demystifying tour of ISO 9000 and ISO 14000In the beginning". Retrieved from http://www.iso.org, 2004

[6] M. Merrill, L. Drake, M. Lacy, and J. Pratt, "Reclaiming instructional design," Educational Technology, Vol. 36, No. 5, pp. 5-7, 1999.

[7] Mawardi, M. Haris, A. Sri, and Asrowi, "The model of instructional design based on self-regulated learning using moodle," Journal of Education and Practice, Online, Vol. 5, No. 22, pp. 131-140, 2014.

[8] R.A. Reiser, and J.V. Dempsey, "Trends and Issues in Instructional Design," 2nd ed., Pearson Education, Inc., Upper Saddle River, NJ: 2007.
TABLE II.

RAW GRADES AND PERCENTAGE (\%) OF STUDENTS PERFORMANCES

\begin{tabular}{|l|c|c|c|c|c|c|c|}
\hline & \multicolumn{7}{|c|}{ Raw Grades of Students Performances } \\
\hline & A & B & C & D & F & Total & Mean \\
\hline $2011 / 2012$ & 4 & 6 & 6 & 6 & 28 & 50 & 37 \\
\hline $2012 / 2013$ & 3 & 11 & 18 & 9 & 6 & 47 & 53 \\
\hline $2013 / 2014$ & 6 & 17 & 22 & 12 & 2 & 59 & 56.98 \\
\hline & \multicolumn{7}{|c|}{ Percentage (\% ) Grades of Students Performances } \\
\hline & A & B & C & D & F & Total & Mean \\
\hline $2011 / 2012$ & 8.00 & 12.00 & 12.00 & 12.00 & 56.00 & 100 & 37 \\
\hline $2012 / 2013$ & 6.38 & 23.40 & 38.30 & 19.15 & 12.77 & 100 & 53 \\
\hline $2013 / 2014$ & 10.17 & 28.81 & 37.29 & 20.34 & 3.39 & 100 & 56.98 \\
\hline
\end{tabular}

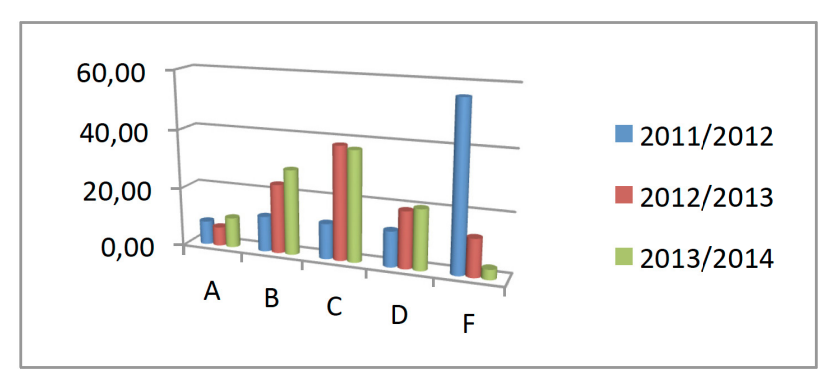

Figure 6. Graphs of Students Performances

[9] R.M. Isiaka, E.O. Omidiora, S.O. Olabiyisi, and O.O. Okediran, "Mamdani fuzzy model for learning activities evaluation," International Journal of Applied Information System (IJAIS), Vol. 7, No. 3, New York, USA, 2014.

[10] R.Reiser, and J. Dempsey, "Trends and issues in instructional technology," Pearson Education, Inc., Boston, 2012.

[11] T. Winterstein, "402 Getting Started with eLearning Standards and SCORM," HunterStone, USA. Inc., 2007

\section{AUTHORS}

R.M. Isiaka is a $\mathrm{PhD}$ Student in the Department of Computer Science and Engineering, Ladoke Akintola University of Technnology, Ogbomosho, Nigeria. He is a lecturer in the Department of Computer, Library and Information Science, Kwara State University, Malete, Ilorin, Nigeria. (abdulrafiu.isiaka@kwasu.edu.ng).

E. O. Omidiora is a Professor of Computer Engineering in the Department of Computer Science and Engineering, Ladoke Akintola University of Technology, Ogbomoso, Nigeria. (eoomidiora@lautech.edu.ng).

S. O. Olabiyisi is a Professor of Computer Science in the Department of Computer Science and Engineering, Ladoke Akintola University of Technology, Ogbomoso, Nigeria (soolabiyisi@lautech.edu.ng).

O. O. Okediran is a Senior Lecturer in the Department of Computer Science and Engineering, Ladoke Akintola University of Technology, Ogbomoso, Nigeria (oookediran@lautech.edu.ng).

Submitted 05 August 2015. Published as resubmitted by the authors 26 December 2015. 